\title{
Degradabilidade Ruminal In Situ da Matéria Seca e Proteína Bruta das Silagens de Milho e Sorgo e de Alguns Alimentos Concentrados ${ }^{1}$
}

\author{
Adriana de Souza Martins ${ }^{2}$, Lúcia Maria Zeoula ${ }^{3^{*}}$, Ivanor Nunes do Prado ${ }^{3^{*}}$, Elias Nunes \\ Martins $^{3^{*}}$, Vânia Regina Loyola ${ }^{4}$
}

\begin{abstract}
RESUMO - A degradação ruminal da matéria seca (MS) e a da proteína bruta (PB) de alguns alimentos foram deterninadas pela técnica in situ, usando-se três vacas Holandesa. Os alimentos concentrados foram moídos em peneira de 2 mm e os volumosos e a raspa de mandioca, em peneira de $5 \mathrm{~mm}$, e incubados em sacos de náilon ( $53 \mu)$. A degradabilidade efetiva (DE) da MS (5\%/h) de silagem de milho, silagem de sorgo, milho, sorgo, farelo de trigo, triticale, raspa de mandioca, polpa cítrica, farelo de soja, farelo de algodão e farinha de carne e ossos foi, respectivamente: 54,$8 ; 46,0 ; 37,6 ; 54,3 ; 80,4 ; 88,7 ; 75,0,67,5 ; 74,1 ; 65,9$; e 39,4\%. As degradabilidades efetivas da PB, 70,$4 ; 67,9 ; 40,2 ; 42,7 ; 86,5 ; 89,3 ; 71,7 ; 62,1 ; 57,3 ; 81,4 ;$ e 47,5\%, respectivamente. Foi realizado agrupamento dos alimentos quanto à dinâmica de degradação ruminal da MS e PB foram por meio do método de Tocher. A fração potencialmente degradável e a sua taxa de degradação foram as variáveis de maior poder discriminatório na formação dos grupos.
\end{abstract}

Palavras-chave: agrupamento, alimentos, vacas Holandesa, volumosos

\section{Ruminal in situ Degradability of Dry Matter and Crude Protein of Corn and Sorghum Silages and Some Concentrate Feeds}

\begin{abstract}
The ruminal dry matter(DM) and crude protein (CP) degradability of some feeds were evaluated by the in situ technique, using three Holstein cows. The concentrate feeds were ground through a $2 \mathrm{~mm}$ screen and the forage and the cassava root, in $5 \mathrm{~mm}$ screen, and incubated in nylon bag $(53 \mu)$. The effective degradability (ED) of DM (5\%/h) for corn silage, sorghum silage, corn, sorghum, wheat bran, triticale, cassava scraping, citrus pulp, soybean meal, cottonseed meal and meat and bone meal was: 54.8, 46.0, 37.6, 54.3, 80.4, 88.7, 75.0, 67.5, 74.1, 65.9, and 39.4\%, respectively. The effective degradabilities CP were: 70.4, 67.9, 40.2, 42.7, 86.5, 89.3, 71.7, 62.1, 57.3, 81.4 , and $47.5 \%$, respectively. The feed group was made according to ruminal DM and CP degradation dynamics, by means of Tocher method. The potentially degradable fraction and its degradation rate were the variables of the highest discrimination power for the group formation.
\end{abstract}

Key Words: grouping, feedstuffs, Holstein cows, forage

\section{Introdução}

A produção de ruminantes vem sendo explorada levando-se em consideração a integração dos nutrientes com os mecanismos biológicos do organismo animal, visando melhorar a qualidade dos produtos comercializados e o bem-estar e a saúde do animal. Para estas espécies, o rúmen desempenha um papel fundamental pelo seu funcionamento e dinâmica, constituindo-se em um órgão de transformação e aproveitamento dos alimentos.

Ao longo dos anos, houve considerável avanço na nutrição de ruminantes. Entretanto, este progresso, na maioria das vezes, baseou-se em determinações empíricas que desconsideravam as múltiplas interrelações microbianas no rúmen (RUSSELL et al., 1992). Segundo SNIFFEN et al. (1992), os alimentos utilizados nas dietas dos ruminantes devem ser fracionados para sua adequada caracterização. Dessa forma, o estudo da cinética da degradação ruminal vem sendo pesquisado nos últimos anos com diferentes alimentos utilizados na nutrição de ruminantes e os resultados obtidos têm possibilitado aos nutricionistas o balanceamento de rações, visando atender às exigências dos microrganismos e do animal hospedeiro (VALADARES FILHO, 1994; HUNTINGTON e GIVENS, 1995). Os sistemas britânico (AGRICULTURAL AND FOOD RESEARCH COUNCIL - AFRC, 1994) e americano (NATIONAL RESEARCH COUNCIL - NRC,

\footnotetext{
${ }^{1}$ Parte da Dissertação de Mestrado do primeiro autor.

${ }^{2}$ Estudante de Mestrado em Zootecnia - UEM - Maringá, PR.

${ }^{3}$ Professor do Departamento de Zootecnia - Universidade Estadual de Maringá. Av. Colombo, 5790, CEP $87020-900$ - Maringá-Pr.

${ }^{4}$ Zootecnista, MSc, UEM.

${ }^{*}$ Pesquisador do CNPq.
} 
1996) calculam as exigências protéicas em termos de proteína metabolizável, ou seja, aminoácidos absorvidos no intestino delgado.

O fluxo de proteína microbiana para o intestino é influenciado pelas taxas de degradação e disponibilidade ruminal dos carboidratos e proteínas (HERRERA-SALDANA et al., 1990; ALDRICH, 1996). O fornecimento de dietas sincronizadas, ou seja, quando carboidrato e proteína são fermentados à taxa equivalente de degradação, promove a maximização da síntese de proteína microbiana no rúmen e aumenta a quantidade de proteína metabolizável ingerida.

Granulometria do alimento, tempo de retenção no rúmen, proporção volumoso/concentrado, tempo de reciclagem dos compostos nitrogenados, quantidade de alimento ingerido, processamento físico ou químico e fonte protéica utilizada na dieta são fatores que podem influenciar a degradação da proteína no rúmen (PEREIRA et al., 1995; ALDRICH, 1996; e ZEOULA et al., 1996). As diferenças nas caraterísticas de degradação dos alimentos repercutem na dinâmica e no equilíbrio dos nutrientes disponíveis para os microrganismos do rúmen (McCARTHY et al., 1989).

O método de degradação in situ consiste em supor que os alimentos e seus constituintes sejam compostos de três frações distintas: fração "a", que representa a fração solúvel do alimento, podendo ser utilizada imediatamente pelos microrganismos do rúmen; fração "b", que corresponde à fração potencialmente degradável, segundo uma velocidade relativa supostamente constante, conforme o tipo de alimento e o parâmetro c que corresponde à taxa de degradação da fração "b". Esta técnica permite a avaliação rápida e simples da degradação do material contido nos sacos de náilon, em função de seu tempo de incubação no rúmen, sendo usada por muitos pesquisadores para caracterização dos alimentos.

O objetivo deste trabalho foi avaliar pela técnica in situ a degradabilidade efetiva da matéria seca (MS) e proteína bruta (PB) das silagens de milho e sorgo do milho, sorgo, farelo de trigo, triticale, da raspa de mandioca, polpa cítrica, do farelo de soja, farelo de algodão e da farinha de carne e ossos e agrupá-los quanto as suas características de degradação ruminal.

\section{Material e Métodos}

O experimento foi conduzido na Fazenda Experimental de Iguatemi (FEI) e no Laboratório de Nutri- ção Animal da Universidade Estadual de Maringá (UEM). Foram utilizadas três vacas Holandesa, portadoras de cânulas ruminais, secas e não-gestantes, com peso médio de $500 \mathrm{~kg}$. Cada animal recebeu $3 \mathrm{~kg}$ de ração concentrada (com $20,1 \%$ de $\mathrm{PB}$ e $81,1 \%$ de NDT, na MS) e $22 \mathrm{~kg}$ de silagem de milho por dia. $\mathrm{Na}$ Tabela 1 encontra-se a composição química dos ingredientes das rações e dos alimentos incubados.

Foi determinada a degradabilidade ruminal da matéria seca (MS) e da proteína bruta (PB) das silagens de milho e sorgo, do milho, sorgo, farelo de trigo, triticale, da raspa de mandioca, polpa cítrica, do farelo de soja, farelo de algodão e da farinha de carne e ossos pela técnica de degradação in situ. Os alimentos concentrados foram moídos em peneira de $2 \mathrm{~mm}$ com exceção da raspa de mandioca $(5 \mathrm{~mm})$ e os volumosos foram moídos em peneira de $5 \mathrm{~mm}$ para posterior incubação.

Os alimentos foram incubados em sacos de náilon (53 micras), com dimensões de $10 \times 17 \mathrm{~cm}$, totalizando 5,5 gramas de MS de cada alimento. Os alimentos concentrados foram incubados nos seguintes tempos, em ordem decrescente: 48, 24, 20, 16, 12, 8, 6, 4 e $2 \mathrm{~h}$ (NOCEK, 1997). As silagens de milho e sorgo foram incubadas nos tempos 72, 48, 36, 24, 6 e $4 \mathrm{~h}$ (NOCEK, 1997). Foram incubados dois alimentos por vaca, em triplicata, e para os alimentos concentrados foram incubados quatro sacos no último tempo, totalizando 56 sacos/vaca. O tempo $0 \mathrm{~h}$ foi, posteriormente, lavado com os demais sacos em máquina de lavar por 45 min e representou a fração solúvel da MS e PB.

Foram feitas análises de MS, PB, fibra em detergente neutro (FDN) e energia bruta (EB) dos ingredientes da ração fornecida e de MS e PB dos alimentos, antes e após a incubação, segundo as metodologias descritas por SILVA (1990).

Os dados sobre o desaparecimento da matéria seca e proteína bruta foram ajustados por regressão não-linear, que prediz a degradabilidade potencial (DP) dos alimentos por meio do modelo proposto por MEHEZ e ORSKOV (1977):

$$
\mathrm{DP}=\mathrm{a}+\mathrm{b}\left(1-\mathrm{e}^{-\mathrm{ct}}\right)
$$

em que a é fração solúvel; b, fração potencialmente degradável; e c, taxa de degradação da fração "b".

A degradabilidade efetiva (DE) foi calculada segundo o modelo matemático proposto por ORSKOV e Mc DONALD (1979):

$$
\mathrm{DE}=\mathrm{a}+((\mathrm{b} * \mathrm{c}) /(\mathrm{c}+\mathrm{k}))
$$

em que $\mathrm{k}$ é taxa estimada de passagem de sólidos no rúmen.

O agrupamento dos alimentos foi realizado consi- 
Rev. bras. zootec.

Tabela 1 - Composição química (\%MS) dos ingredientes da ração e dos alimentos incubados

Table 1 - Chemical composition (\%DM) of the ingredients of the diet and of the incubated feed

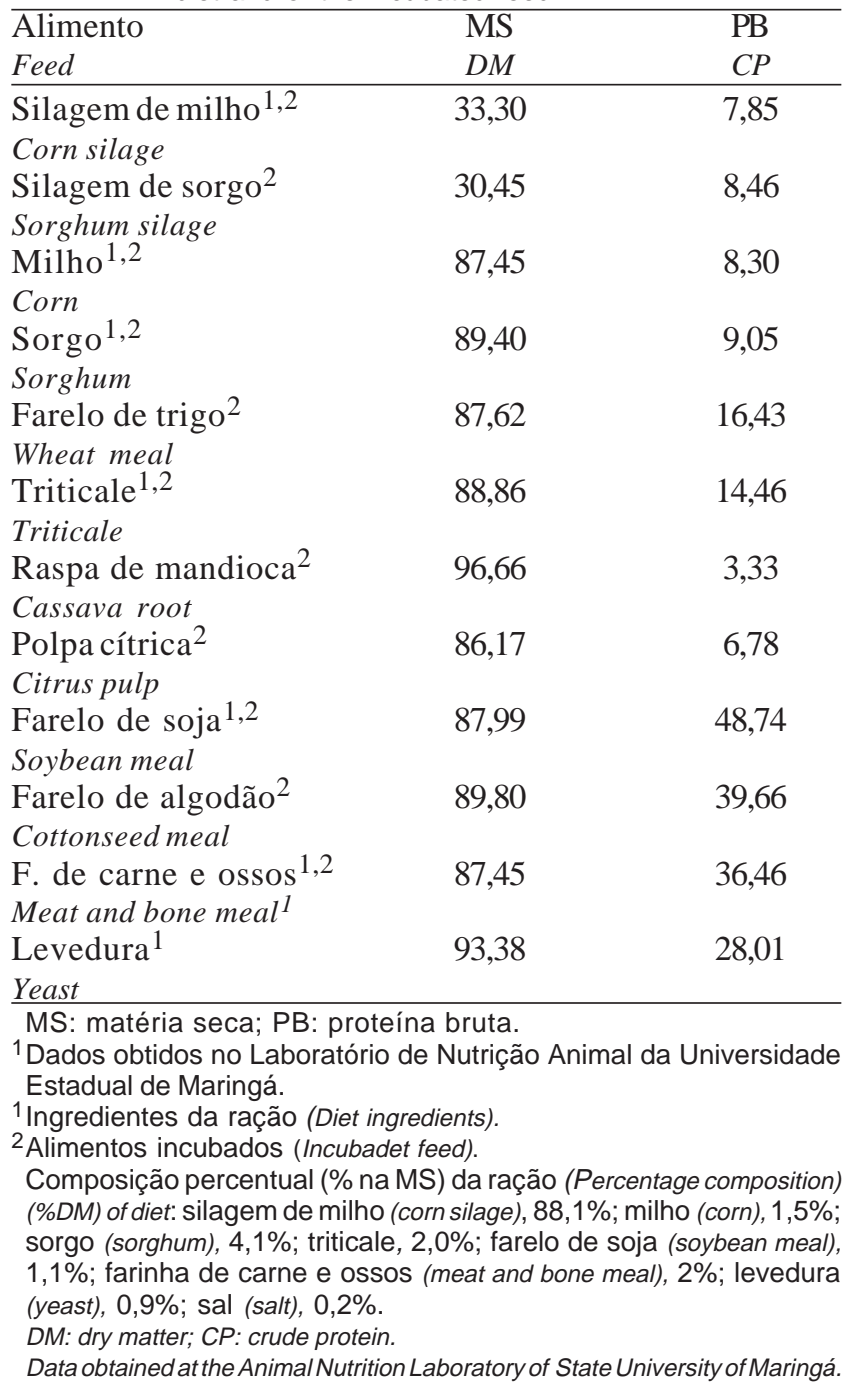

derando os parâmetros "a", "b" e "c" e a degradabilidade efetiva (DE), para taxa de passagem de $5 \% / \mathrm{h}$, utilizando-se o método não-hierárquico proposto por Tocher (RAO, 1952; CRUZ e REGAZZI, 1994; e SAKAGUTI et al., 1996), tendo como critério de dissimilaridade o momento produto de Pearson, para avaliar as distâncias intra e entre grupos, por meio do programa SAEG.

\section{Resultados e Discussão}

Os parâmetros "a", "b" e "c" e as degradabilidades efetivas (DE) da MS, para taxas de passagem de 2, 5 e $8 \% / \mathrm{h}$, são mostrados na Tabela 2 . A silagem de milho apresentou valor da fração solúvel de $45,2 \%$ e baixa taxa de degradação da fração "b" $(1,1 \% / h)$ da MS, provavelmente devido ao elevado teor de FDN $(45,8 \%)$, semelhante ao referenciado pelo NRC (1996). A DE da MS encontrada por PEREIRA et al. (1997b) para este alimento, sem considerar o lag time, foi de $45,1 \%$, inferior ao valor encontrado $(54,8 \%)$, para taxa de passagem de $5 \% / \mathrm{h}$.

A silagem de sorgo apresentou o mesmo valor para a taxa de degradação da MS, em relação à silagem de milho, e fração solúvel obtida foi de $34,7 \%$. O valor encontrado para a DE foi $46,0 \%$. Fatores como teor de MS da silagem, tipo de fermentação e conteúdo de carboidratos solúveis também podem contribuir para diferentes taxas de degradação ruminal.

Analisando os parâmetros de degradação da MS do milho, foi encontrado para a fração "a" valor superior $(32,9 \%)$ ao observado por PEREIRA et al. (1997a), que foi de 20,3\%. Entretanto, a taxa de degradação da fração "b" $(0,4 \% / h)$ foi inferior à obtida por esses autores $(3,7 \% / \mathrm{h})$. A DE da MS obtida obtida neste trabalho $(37,6 \%)$ foi pouco superior à obtida por VALADARES FILHO et al. (1991) de $36,7 \%$, com vacas após o pico de lactação, para taxa de passagem de $5 \% / \mathrm{h}$.

O sorgo apresentou valor de DE da MS bastante superior $(54,3 \%)$ ao obtido por VALADARES et al. (1991), que foi de (29\%), para taxa de passagem de $5 \% / h$. ROSSI JR. et al. (1997) também encontraram valor de DE da MS inferior (46,2\%) ao observado neste trabalho, sem considerar o lag time. A fração solúvel deste alimento foi de $49,3 \%$ e a taxa de degradação "c", 6\%/h. Segundo ROONEY e PLFUGFELDER (1986), o sorgo apresenta digestibilidade inferior à do milho, devido, principalmente, à presença de endosperma periférico no sorgo, o qual é extremamente denso e resistente à digestão. Neste trabalho, foram encontrados para o sorgo valores superiores de DE em relação ao milho, que provavelmente poderia ter ocorrido em função da ocorrência de maior perda de partículas do sorgo em relação ao milho ou por outro fator relacionado à metodologia utilizada na avaliação in situ.

$\mathrm{O}$ farelo de trigo apresentou alto valor para a fração solúvel $(61,5 \%)$, porém sua taxa de degradação foi inferior $(11,7 \% / \mathrm{h})$ à do triticale. A DE da MS deste alimento foi inferior $(60,2 \%)$ ao valor médio de $80,4 \%$, encontrado por VALADARES FILHO (1994) em uma coletânea de dados, para $5 \% / \mathrm{h}$ de taxa de passagem.

$\mathrm{O}$ triticale apresentou elevados valores para a fração solúvel $(69,9 \%)$ e a taxa de degradação $(23,8 \% / h)$. A DE também foi elevada, caracterizando este alimento como 
MARTINS et al.

Tabela 2 - Fração solúvel (a) e potencialmente degradável (b), taxa de degradação (c) e degradação (DE) da MS dos alimentos para taxas de passagem de 2; 5; e 8\%/h

Table 2 - Soluble (a), potentially degradable fraction (b), degradation rate (c) and DM effective degradability of feed at passage rates of 2,5 , and $8 \% / h$

\begin{tabular}{|c|c|c|c|c|c|c|}
\hline \multirow[b]{2}{*}{$\begin{array}{l}\text { Alimento } \\
\text { Feed }\end{array}$} & \multirow[b]{2}{*}{$\mathrm{a}$} & \multirow[b]{2}{*}{$\mathrm{b}$} & \multirow[b]{2}{*}{$\mathrm{c}$} & \multicolumn{3}{|c|}{$\mathrm{DE}(\% / \mathrm{h})$} \\
\hline & & & & 2 & 5 & 8 \\
\hline $\begin{array}{l}\text { Silagem de milho } \\
\text { Corn silage }\end{array}$ & 45,2 & 54,8 & 0,011 & 63,2 & 54,8 & 51,7 \\
\hline $\begin{array}{l}\text { Silagem de sorgo } \\
\text { Sorghum silage }\end{array}$ & 34,7 & 65,3 & 0,011 & 56,6 & 46,0 & 42,4 \\
\hline $\begin{array}{l}\text { Milho } \\
\text { Corn }\end{array}$ & 32,9 & 67,1 & 0,004 & 43,2 & 37,6 & 36,00 \\
\hline $\begin{array}{l}\text { Sorgo } \\
\text { Sorghum }\end{array}$ & 49,3 & 50,7 & 0,060 & 59,7 & 54,3 & 52,6 \\
\hline $\begin{array}{l}\text { Farelo de trigo } \\
\text { Wheat bran }\end{array}$ & 61,5 & 28,7 & 0,117 & 85,1 & 80,4 & 77,5 \\
\hline $\begin{array}{l}\text { Triticale } \\
\text { Triticale }\end{array}$ & 69,9 & 22,7 & 0,238 & 90,8 & 88,7 & 86,9 \\
\hline $\begin{array}{l}\text { Raspa de mandioca } \\
\text { Cassava root }\end{array}$ & 55,6 & 37,9 & 0,100 & 81,9 & 75,0 & 71,4 \\
\hline $\begin{array}{l}\text { Polpa cítrica desidratada } \\
\text { Citrus pulp dehydrataded }\end{array}$ & 44,9 & 55,1 & 0,035 & 79,8 & 67,5 & 61,7 \\
\hline $\begin{array}{l}\text { Farelo de soja } \\
\text { Soybean meal }\end{array}$ & 37,4 & 62,3 & 0,080 & 85,6 & 74,1 & 67,3 \\
\hline $\begin{array}{l}\text { Farelo de algodão } \\
\text { Cottonseed meal }\end{array}$ & 42,8 & 36,5 & 0,090 & 72,3 & 65,9 & 61,9 \\
\hline $\begin{array}{l}\text { Farinha de carne e ossos } \\
\text { Meat and bone meal }\end{array}$ & 24,5 & 45,5 & 0,075 & 46,7 & 39,4 & 36,3 \\
\hline
\end{tabular}

sendo de alta e rápida degradação ruminal para MS.

A raspa de mandioca também apresentou valor elevado para a fração "a" $(55,6 \%)$ e a fração "c" apresentou valor de $10 \% / \mathrm{h}$. A DE da MS obtida foi de $75 \%$, superior ao valor de $68,1 \%$, para este alimento, encontrado por VALADARES FILHO (1994), para $5 \% / \mathrm{h}$ de taxa de passagem.

A polpa cítrica desidratada apresentou valor de DE da MS de 67,5\%, para taxa de passagem de 5\%/h. A fração solúvel obtida foi de $44,9 \%$ e a taxa de degradação da fração "b”, 3,5\%/h. Este alimento é rico em pectina, um carboidrato complexo estrutural de rápida degradação ruminal, e está prontamente disponível para promover a máxima produção de massa microbiana (VAN SOEST, 1994; SMET et al., 1995). As diferenças no processo de desidratação, fonte e variedade das frutas e tipo de operação para a obtenção do resíduo, podem resultar em variações no conteúdo de nutrientes da polpa seca resultante (AMMERMAN e HENRI, 1993).

Os valores dos parâmetros "a", 'b" e "c" para a MS do farelo de soja obtidos neste trabalho foram semelhantes aos obtidos por ROSSI JR. et al. (1997), que foram respectivamente, 37,3\%, 62,1\% e 8,8\%/h. Entretanto, a DE da MS para este alimento, para taxa de passagem de $2 \% / \mathrm{h}$, foi pouco superior $(85,6 \%)$ ao valor médio observado por VALADARES FILHO (1994) para essa mesma taxa de passagem, $82,4 \%$.

O farelo de algodão apresentou valor de 65,9\% para a DE da MS, para taxa de passagem de $5 \% / \mathrm{h}$, próximo ao obtido por PEREIRA et al. (1997a), $67,3 \%$. A fração "a" obtida para este alimento foi de $42,8 \%$ e a taxa de passagem, $9 \% / \mathrm{h}$.

A farinha de carne e ossos apresentou baixos valores para a fração solúvel $(24,5 \%)$ e a DE $(39,4 \%)$ em relação aos demais grupos. Entretanto, sua taxa de degradação $(7,5 \% / \mathrm{h})$ apresentou valor médio. A DE da MS encontrada para este alimento foi superior à encontrada por VILELA et al. (1994), de 21,8\%, para taxa de passagem de $5 \% / \mathrm{h}$.

$\mathrm{O}$ agrupamento da MS dos alimentos encontra-se na Tabela 3. Os alimentos, quanto às características de degradação ruminal da MS, foram divididos em cinco grupos, e as contribuições das variáveis "a", "b" e "c" e DE para o agrupamento dos alimentos foram 21,$8 ; 29,1 ; 40 ;$ e 9,1\%, respectivamente. Estes valores medem a contribuição relativa das variáveis na discriminação dos grupos. Desse modo, a taxa de degradação (c) da fração "b", seguida da fração "b", foi a variável de maior poder discriminatório na formação dos grupos. Isso significa que os alimentos podem apresentar valores de DE da MS semelhantes, 
Rev. bras. zootec.

Tabela 3 - Agrupamento dos alimentos quanto à degradação ruminal da MS, usando-se os parâmetros "a", "b" e "c" e a degradação efetiva (DE) para taxa de passagem de $5 \% / \mathrm{h}$

Table 3 - Grouping of feed according to ruminal DM degradation, using "a", "b" and "c" parameters and effective degradability at passage rate of $5 \% / h$

\begin{tabular}{|c|c|c|}
\hline $\begin{array}{l}\text { Grupo }{ }^{1} \\
\text { Group }^{1}\end{array}$ & $\begin{array}{l}\text { Característica de degradação } \\
\text { ruminal } \\
\text { Ruminal degradation characteristic }\end{array}$ & $\begin{array}{l}\text { Alimento } \\
\text { Feed }\end{array}$ \\
\hline \multirow{8}{*}{1} & $\mathrm{a}=42,8-69,9 \%$ & Farelo de trigo \\
\hline & & Wheat meal \\
\hline & $b=22,7-37,9 \%$ & Triticale \\
\hline & & Triticale \\
\hline & $\mathrm{c}=9,0-23,8 \% / \mathrm{h}$ & Raspa de mandioca \\
\hline & & Cassava root \\
\hline & $\mathrm{DE}=65,9-88,7 \%$ & Farelo de algodão \\
\hline & & Cottonseed meal \\
\hline \multirow{4}{*}{2} & $a=37,4 \%$ & \\
\hline & $\mathrm{b}=62,3 \%$ & Farelo de soja \\
\hline & $\mathrm{c}=8,0 \% / \mathrm{h}$ & Soybean meal \\
\hline & $\mathrm{DE}=74,1 \%$ & \\
\hline \multirow{4}{*}{3} & $\mathrm{a}=49,3 \%$ & \\
\hline & $\mathrm{b}=50,7 \%$ & Sorgo \\
\hline & $c=6,0 \% / h$ & Sorghum \\
\hline & $\mathrm{DE}=54,3 \%$ & \\
\hline \multirow{8}{*}{4} & $a=32,9-45,2 \%$ & Silagem de milho \\
\hline & & Corn silage \\
\hline & $b=54,8-65,3 \%$ & Silagem de sorgo \\
\hline & & Sorghum silage \\
\hline & $\mathrm{c}=0,4-3,5 \% / \mathrm{h}$ & Milho \\
\hline & & Corn \\
\hline & $\mathrm{DE}=37,6-67,5 \%$ & Polpa cítrica \\
\hline & & Citrus pulp \\
\hline \multirow{4}{*}{5} & $\mathrm{a}=24,5 \%$ & \\
\hline & $b=45,5 \%$ & Farinha de carne e ossos \\
\hline & $\mathrm{c}=7,5 \% / \mathrm{h}$ & Meat and bone meal \\
\hline & $\mathrm{DE}=39,4 \%$ & \\
\hline
\end{tabular}

porém distribuídos em mais de um grupo, diferenciados principalmente pela velocidade de degradação da fração potencialmente degradável da MS e pela própria fração "b".

No grupo 1, estão incluídos o farelo de trigo, o triticale, a raspa de mandioca e o farelo de algodão, cujas taxas de degradação ruminal variaram de 9 (farelo de algodão) a 23,8\%/h (triticale), sendo classificados como alimentos de rápida degradação ruminal da MS. A DE da MS variou de 65,9 (farelo de algodão) a 88,7\% (triticale). A fração solúvel da MS deste grupo de alimentos apresentou valores entre 42,8 (farelo de algodão) e 69,9\% (triticale).

No grupo 2 foi incluído apenas o farelo de soja, com valores intermediários para as frações "a" $(37,4 \%)$ e "c" (8\%/h) e elevado para a DE $(74,1 \%)$ em relação aos demais grupos, sendo caracterizado como alimento com média taxa de degradação ruminal para a MS.

O sorgo fez parte do grupo 3, apresentando taxa de degradação da fração " $b$ " de $6,0 \% / \mathrm{h}$ e DE de $54,3 \%$, sendo também caracterizado como alimento de média taxa de degradação para a MS, em relação aos grupos formados, e diferenciado do grupo 2, por apresentar menor fração potencialmente degradável e menor valor de DE da MS. Como comentado anteriormente, os valores das frações "a" e "b", a taxa de degradação (c) e a DE obtidos para o sorgo foram considerados altos em relação aos valores obtidos para o milho. Isto provavelmente justificaria a não inclusão do sorgo no mesmo grupo do milho, em que o agrupa- 
mento o classificou como sendo de intermediária taxa de degradação para a MS e o milho como sendo de baixa taxa dedegradação ruminal para a MS.

As silagens de milho e sorgo, o milho e a polpa cítrica fizeram parte do grupo 4. Estes alimentos apresentaram baixa taxa de degradação, a qual variou de 0,4 (milho) a 3,5\%/h (polpa cítrica). Os valores de DE da MS variaram de 37,6 (milho) a $67,5 \%$ (polpa cítrica) e a fração solúvel oscilou entre 32,9 (milho) e 45,2\% (silagem de milho). Estes alimentos foram classificados como alimentos de lenta taxa de degradação ruminal da MS. A farinha de carne e ossos fez parte do grupo 5, caracterizada como alimento de média taxa de degradação da MS, em função do valor médio obtido para a taxa de degradação $(7,5 \% / \mathrm{h})$. Este alimento também foi classificado como sendo de baixa degradação ruminal devido aos baixos valores de DE.

Os parâmetros "a", "b" e "c" e as degradabilidades efetivas (DE) da $\mathrm{PB}$, para taxas de passagem de 2 ; 5 e $8 \% / h$, são mostrados na Tabela 4 . A fração "a" da PB da silagem de milho apresentou valor elevado $(61,5 \%)$, semelhante ao valor encontrado por ROSSI JR. et al. (1997), que foi de 62,6\%. Provavelmente, o valor elevado da fração "a" seja atribuído à ocorrência de hidrólise das frações de proteína durante o processo de ensilagem, causando aumento na fração do nitrogênio não-protéico proveniente da proteína verdadeira. Para a DE da PB da silagem de milho, o valor obtido foi de 70,4\%, para $5 \%$ /h de taxa de passagem, sendo inferior ao valor obtido por ROSSI JR. et al. (1997), que foi de 79,9\%.

A silagem de sorgo apresentou valor de DE de $67,9 \%$, para taxa de passagem de $5 \% / \mathrm{h}$, e baixa taxa de degradação $(1,7 \% / \mathrm{h})$.

O valor de DE da PB do milho obtido (40,2\%) foi próximo ao valor de $39,6 \%$, encontrado por VALADARES et al. (1994), para taxa de passagem de $5 \% / \mathrm{h}$. Entretanto, foi inferior ao valor obtido por PEREIRA et al. (1997a), que foi de 62,5\%. Este alimento apresentou lenta degradação ruminal, sendo o valor da fração "c" de $0,2 \% /$ h e a fração solúvel $38 \%$.

A DE da PB do sorgo, para taxa de passagem de $5 \% / \mathrm{h}$ foi superior $(42,7 \%)$ ao valor encontrado por VALADARES et al. (1991), que foi de 29,2\%, e inferior ao observado por ROSSI JR. (1997), de $59,7 \%$. A taxa de degradação da fração "b" encontrada foi de $5 \% / \mathrm{h}$.

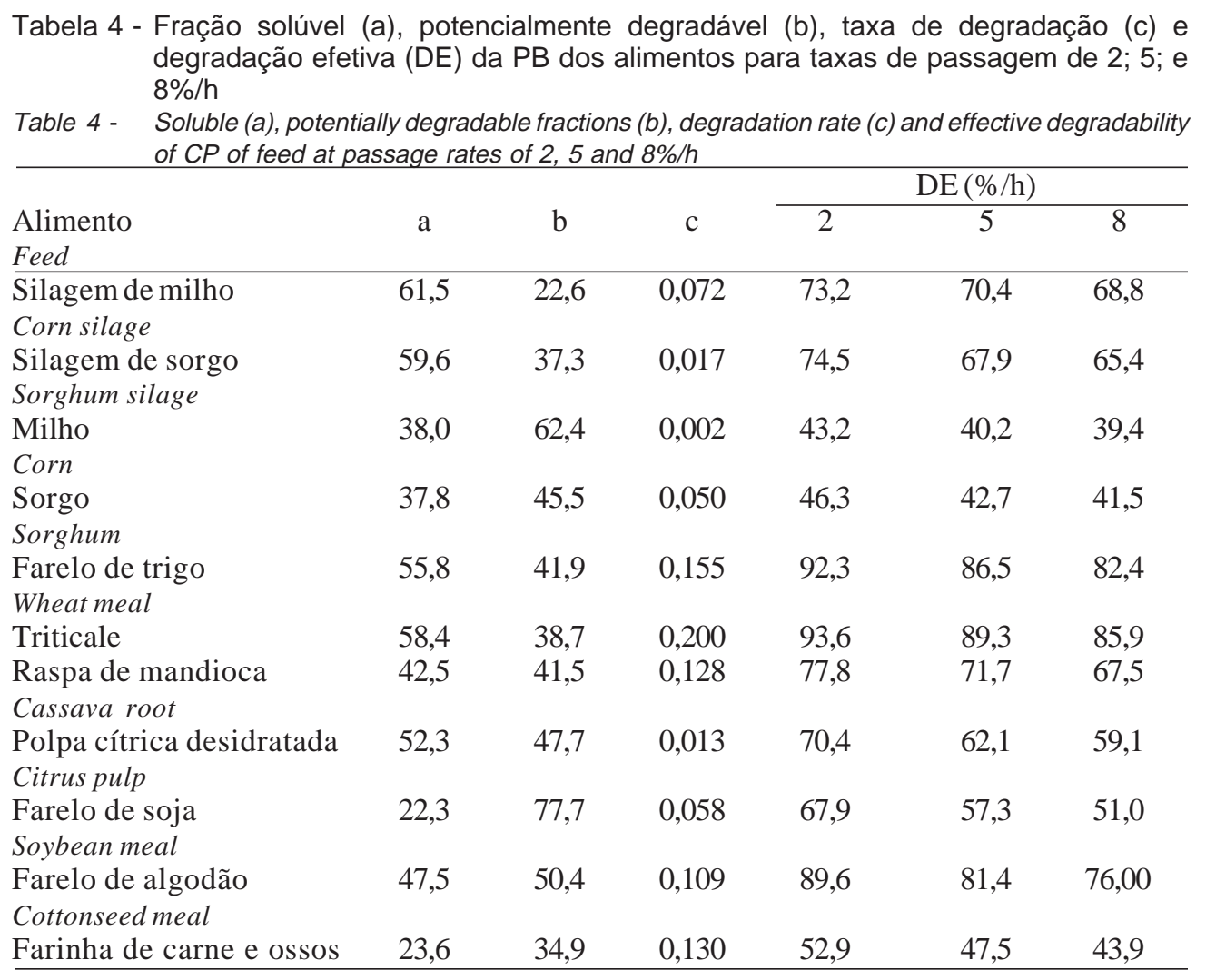


Rev. bras. zootec.

$O$ farelo de trigo apresentou valores da fração "a" e DE da PB próximos aos valores encontrados para o triticale, entretanto sua taxa de degradação foi pouco inferior $(15,5 \% / \mathrm{h})$. VALADARES FILHO (1994) encontrou para o farelo de trigo valor médio para a DE da PB inferior $(75,5 \%)$ ao observado neste trabalho $(86,5 \%)$ para taxa de passagem de $5 \% / \mathrm{h}$.

A fração "a " e a DE da PB do triticale apresentaram valores elevados. A taxa de degradação de $20 \% / \mathrm{h}$, juntamente com os demais parâmetros, evidencia que a proteína deste alimento é de alta e rápida degradação ruminal.

A raspa de mandioca apresentou taxa de degradação da proteína $12,8 \% / \mathrm{h}$ e, portanto, a proteína da raspa caracteriza-se como de rápida degradação ruminal. Todavia, vale ressaltar que este alimento apresenta baixo teor de PB (3,3\%). ALMEIDA et al.
(1993) encontraram valor de 39,5\% para a DE da PB da raspa de mandioca, sendo bastante inferior ao valor observado $(71,7 \%)$ para taxa de passagem de $5 \% / \mathrm{h}$.

A polpa cítrica desidratada apresentou valor de DE da PB de 62,2\%. O NRC (1996) preconiza 70\% de degradabilidade ruminal para a PB deste alimento. A taxa de degradação "c" da PB encontrada apresentou valor baixo $(1,3 \% / \mathrm{h})$.

Para a DE da PB do farelo de soja, foi obtido valor de $51 \%$, para taxa de passagem de $8 \% / \mathrm{h}$. MADSEN e HVELPLUND (1994) e VALADARES FILHO (1994) encontraram valores superiores ao observado, de 63,8 e 55,6\%, respectivamente, para a mesma taxa de passagem. A DE da PB obtida no presente trabalho para o farelo de soja foi, em média, $41 \%$ inferior à do farelo de algodão, entretanto, o NRC (1996) apresentou valor de degradabilidade ruminal da PB

Tabela 5 - Agrupamento dos alimentos quanto à degradação ruminal da PB usando-se os parâmetros "a", "b" e "c" e a degradabilidade efetiva (DE) para taxa de passagem de $5 \% / \mathrm{h}$

Table 5- Grouping of feed according to ruminal CP degradation, using "a", "b" and "c" parameters and effective degradability at passage rate $5 \% / h$

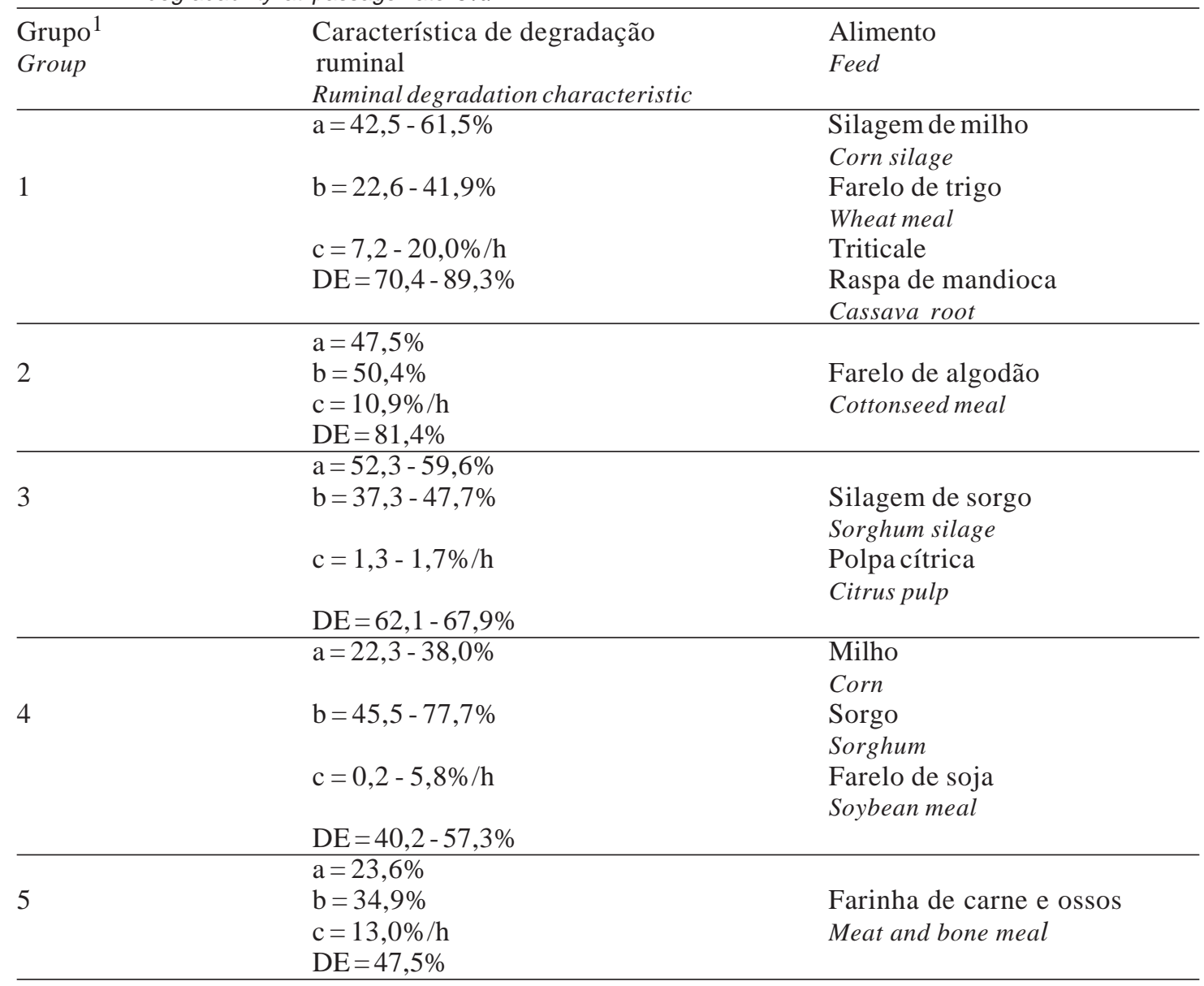

${ }^{1}$ Agrupamento segundo o método não-hierárquico proposto por Tocher.

Contribuição das variáveis para a formação dos grupos: $a=18,2 \% ; b=45,6 \% ; c=34 \% ; D E=1,8 \%$.

1 Grouping by the Tocher non-hierarchical method.

Variables contribuition for groups forming: $a=18.2 \% ; b=45.6 \% ; c=34 \%$; $E D=1.8 \%$. 
do farelo de soja (66\%) superior à do farelo de algodão (57\%).

Para a DE da PB do farelo de algodão, foi obtido valor de $81,4 \%$, semelhante ao observado por VALADARES FILHO (1994), que foi de 82,2\%. Entretanto, PEREIRA et al. (1997a) obtiveram valor pouco inferior $(79,4 \%)$. CASTILHO et al. (1993) encontraram valor de DE inferior $(54,3 \%)$ para taxa de passagem de $5 \% / \mathrm{h}$. Esta diferença pode ter ocorrido em razão do teor de $\mathrm{PB}$ do farelo de algodão utilizado neste trabalho e em CASTILHO et al. (1993), que foi de 39,7 e $31 \%$, respectivamente. A menor proporção de casca e, conseqüentemente, a maior porção protéica conferem ao material uma textura mais fina, que pode favorecer a perda de partículas durante a incubação. A taxa de degradação "c" da proteína deste alimento foi de 10,9\%/h.

A farinha de carne e ossos apresentou valores de DE da PB semelhantes aos obtidos por ARIAS et al. (1992), com teor de PB de $36,2 \%$. A fração solúvel obtida foi de $23,6 \%$ e a taxa de degradação da fração "b", 13\%/h.

$\mathrm{O}$ agrupamento da $\mathrm{PB}$ dos alimentos encontra-se na Tabela 5. Para o agrupamento dos alimentos quanto às características de degradação da proteína, os parâmetros "a", "b" e "c" e a DE contribuíram com 18,$2 ; 45,6 ; 34 \%$; e $1,8 \%$, respectivamente, sendo, também, formados cinco grupos. Verifica-se que a fração potencialmente degradável "b", seguida pela sua taxa de degradação "c", foi a variável que mais contribuiu na divergência entre os grupos e a DE da $\mathrm{PB}$, a de menor contribuição na formação dos grupos.

A silagem de milho, o farelo de trigo, o triticale e a raspa de mandioca formaram o grupo 1 e apresentaram valores elevados para a fração "c", que variaram de 7,2 (silagem de milho) a 20,0\%/h (triticale). A fração "b" apresentou valores entre 22,6 (silagem de milho) e 41,9\% (farelo de trigo) e maiores valores foram observados para a fração solúvel, que variou de 42,5 (raspa de mandioca) a $61,5 \%$ (silagem de milho). A DE da PB variou entre 70,4 ( silagem de milho) e 89,3\% (triticale), mostrando-se alta em relação aos demais alimentos; portanto, a proteína deste grupo de alimentos foi caracterizada como sendo de alta e rápida degradação ruminal.

O farelo de algodão pertenceu ao grupo 2, cuja fração solúvel da proteína foi de $47,5 \%$, e a taxa de degradação da fração "b" e a DE da PB apresentaram valores elevados $(10,9 \% / \mathrm{h}$ e $81,4 \%$, respectiva- mente). A proteína do farelo de algodão também caracteriza-se como de alta degradabilidade e rápida taxa de degradação ruminal, diferenciando-se do grupo 1 pelo maior valor da fração protéica potencialmente degradável $(50,4 \%)$.

A silagem de sorgo e a polpa cítrica desidratada foram incluídas no grupo 3. Os respectivos alimentos apresentaram baixa taxa de degradação, 1,7 e 1,3\%/h, e elevados valores de fração "a" $(59,6 \%$ e $52,3 \%)$ e DE da PB (de 67,9\% e 62,1\%). A proteína presente nestes alimentos caracteriza-se como de lenta taxa de degradação.

O milho, sorgo e farelo de soja pertenceram ao grupo 4 e apresentaram baixos valores da fração "c", que variaram de 0,2 (milho) a 5,8\%/h (farelo de soja), diferenciando do grupo 3 , que também apresenta baixa taxa de degradação para proteína, pelos altos valores de fração "b" e, conseqüientemente, baixos valores da fração "a". A DE deste grupo também foi baixa, variando entre 40,2 (milho) e 57,3\% (farelo de soja). A proteína presente nos alimentos deste grupo também classifica-se como de lenta degradação ruminal.

A farinha de carne e ossos, apesar de apresentar elevada taxa de degradação $(13 \% / \mathrm{h})$, pertenceu ao grupo 5, com baixos valores para a fração "a" $(23,6 \%)$, fração "b" (34,9\%) e para a DE $(47,5 \%)$. A proteína presente na farinha de carne e ossos caracteriza-se como sendo de baixa degradabilidade ruminal, porém com rápida taxa de degradação.

\section{Conclusões}

Os alimentos avaliados pela técnica in situ e por meio da análise de agrupamento, segundo o método de Tocher, foram distribuídos em cinco grupos quanto as suas características de degradação ruminal da MS e PB, sendo que as variáveis de maior poder discriminatório na formação dos grupos foram a fração do alimento com potencial de degradação " $b$ " e a sua taxa de degradação "c", seguida pela fração solúvel "a". A degradabilidade efetiva da MS e PB foi a variável de menor contribuição.

O método de Tocher facilitou a identificação dos grupos de alimentos que apresentaram comportamentos semelhantes quanto à dinâmica de degradação ruminal, permitindo compor rações que visam combinar os alimentos para favorecer a síntese de proteína microbiana. 


\section{Referências Bibliográficas}

AGRICULTURAL AND FOOD RESEARCH COUNCIL AFRC. 1993. Technical committee on responses to nutrients: energy and protein requirements of ruminants. Wallinford: CAB INTERNATIONAL, 159p.

ALDRICH, J.M., HOLDEN, L.A., MULLER, L.D. et al. 1996. Rumen availabilities of nonstructural carbohydrate and protein estimated from in situ incubation of ingredients versus diets. Anim. Feed Sci. Tech., 63(1/4):257-271.

ALMEIDA, G.A.P., VALADARES FILHO, S.C., COELHO DA SILVA, J.F. et al. Degradabilidade in situ da matéria seca e proteína bruta dos ingredientes de cinco rações concentradas, contendo diferentes níveis de degradabilidade de proteína bruta no rúmen, fornecidas para vacas em lactação. In: REUNIÃO ANUAL DA SOCIEDADE BRASILEIRA DEZOOTECNIA, Rio de Janeiro, RJ. Anais...Rio de Janeiro: SBZ, v.30, p.417, 1993.

AMMERMAN, C.B. HENRY, P.R. 1993. Citrus and vegetable products for ruminants animals. Feeding and Nutrition. University of Florida.

ARIAS, A.M.C, VALADARES FILHO, S.C., COELHO DA SILVA, J.F. et al. 1992. Degradabilidade ruminal in situ da matéria seca e proteína bruta de oito alimentos em vacas gestantes alimentadas com feno (80\%) e concentrado (20\%). R. Soc. Bras. de Zootec., 29:500.

CASTILHO, A.A.M., VALADARES FILHO, S.C., COELHO DA SILVA, J.F. et al. 1993. Degradabilidade ruminal da matéria seca e da proteína bruta de alimentos, utilizando-se a técnica dos sacos de náilon, em vacas gestantes alimentadas com feno (80\%) e concentrados (20\%). R. Soc. Bras. Zootec., 22(1):89-98.

CRUZ, C.D., REGAZZI, A.J. 1994. Modelos biométricos aplicados ao melhoramento genético. Viçosa: UFV. Impr. Univ. 390p.

HERRERA-SALDANA, R.E., HUBER, J.T., POORE, M.H. 1990. Dry matter, crude protein and starch degradability of five cereal grains. J. Dairy Sci., 3(9):2386-2393.

HUNTINGTON, J.A. GIVENS, D.I. 1995. The in situ technique for studying the rumen degradation of feeds: A review of the procedure. Nutr. Abs. Rev. (série B), 65(2):63-78.

MASDEN, J., HVELPLUND, T. 1994. Prediction of in situ degradability in the rumen. Results of a European ringtest. Lvrs. Prod. Sci., 39(2):201-212.

McCARTHY, R.D., KLUSMEYER, JR., CLARK, T.H. et al. 1989. Effects of source of protein and carbohydrate on rumen fermentation and passage of nutrients to the small intestine of lactating cows. J. Dairy Sci., 72(8):2002-2016.

MERTENS, D.R., LOFTEN, J.R. 1980. The effect of starch on forage fiber digestion kinetics in vitro. J. Dairy Sci., 63:1437.

NATIONAL RESEARCH COUNCIL - NRC. 1996. Nutrient Requeriments of beef cattle, Washington, D.C. 242p.

NOCEK, J.E. In situ e outros métodos para estimar a proteína ruminal e a digestibilidade da energia: Revisão. In: SIMPÓSIO INTERNACIONAL DE DIGESTIBILIDADE EM RUMINANTES. Lavras, 1997. Anais... Lavras: UFLA-FAEPE, p.241-287, 1997.

NOCEK, J.E. 1988. In situ and other methods to estimate ruminal protein and energy digestibility. A review. J. Dairy Sci., 71(8):2051-2069.

ORSKOV, E.R., Mc DONALD, I. 1979. The estimation of protein degradability in the rumen from incubation measurements weighted according to rate of passage. J. Agric. Sci., 92(2):499.

PEREIRA, J.R.A., BOSE, M.L.V., BOIN, C. 1997a. Avaliação das sub-frações dos carboidratos e das proteínas, usando a metodologia do CNCPS e in situ com bovinos da raça Nelore. Silagem de milho. R. Soc. Bras. Zootec., 26(4):832-837.

PEREIRA, J.R.A., BOSE, M.L.V., BOIN, C. 1997b. Avaliação das sub-frações dos carboidratos e das proteínas, usando a metodologia do CNCPS e in situ com bovinos da raça Nelore. Milho e farelo de algodão. R. Soc. Bras. Zootec., 26(4):838-843.

RAO, R.C. 1952. Advanced statistical methods in biometric research. New York: John Wiley and Sons. 390p.

ROONEY, L.W., PFLUGFELDER, R.L. 1986. Factors affecting starch digestibility with special emphasis on sorghum and corn. J. Anim. Sci., 63:1607-1623.

ROSSI JR., P., SILVA, A.G., WANDERLEY, R.C. et al. 1997. Degradabilidade ruminal da matéria seca e da fração protéica da silagem de milho, do farelo de soja e do sorgo em grão, em bovinos da raça Nelore. Comparação com os dados obtidos pelo CNCPS. R. Soc. Bras. Zootec., 26(3):599-607.

RUSSELL, J.B., O'CONNOR, J.D. et al. 1992. A net carbohydrate and protein system for evaluating cattle diets: I-Ruminal fermentation. J. Anim. Sci., 70:3551-3561.

SAKAGUTI, E.S., SILVA, M.A., REGAZZI, A.J. et al. 1996. Análise de divergência genética entre nove grupos genéticos de coelhos. R. Soc. Bras. Zootec., 25(4):647-660.

SILVA, D.J. 1990. Análise de alimentos: métodos químicos e biológicos. Viçosa: UFV. 165p.

SMET, A.M., BOEVER, J.L., BRABANDER, D.L. et al. 1995. Investigation of dry matter degradation and acidotic effect of some feedstuffs by means of in sacco and in vitro incubations. Anim. Feed Sci Tech., 51:297-315.

SNIFFEN, C.J., O'CONNOR, J.D., VAN SOEST, P.J. et al. 1992. A net carbohydrate and protein system for evaluating cattle diets: II- Carbohydrate and protein availability. $J$. Anim. Sci., 70:3562-3577.

VALADARES FILHO, S.C., COELHO DA SILVA, J.F.C., LEÃO, M.I. et al. 1991. Degradabilidade in situ da proteína bruta e matéria seca de alguns alimentos em vacas gestantes e lactantes. R. Soc. Bras. Zootec., 20(1):111-122.

VALADARES FILHO, S.C. Utilização da técnica in situ para avaliação dos alimentos. In: SIMPÓSIO INTERNACIONAL DE PRODUÇÃO DE RUMINANTES; REUNIÃO ANUAL DA SOCIEDADE BRASILEIRA DE ZOOTECNIA, 31, Maringá, 1994. Anais... Maringá: SBZ, p.95-118, 1994.

VAN SOEST, P.J. 1994. Nutritional Ecology of the Ruminant. Comstock Publ. Assoc. 476p.

VILELA, G.L., VALADARES FILHO, S.C., COELHO DA SILVA, J.F.C. et al. 1994. Degradabilidade in situ da matéria seca e da proteína bruta e proteína efetivamente degradada no rúmen, de vários alimentos. R. Soc. Bras. Zootec., 23(3):342-351.

ZEOULA, L.M., PRADO, I.N., SANTOS, G.T. et al. Degradabilidade In situ do farelo de canola moído e peletizado. In: REUNIÃO ANUAL DA SOCIEDADE BRASILEIRA DE ZOOTECNIA, 33, Fortaleza, CE. Anais...Fortaleza: SZB, v.3, p.344-346, 1996.
Recebido em: 22/06/98 Aceito em: 08/03/99 